\title{
Electric vehicles revolution: The future, challenges, and prospects in the Arab countries
}

\author{
Abdussalam Ali Ahmed 1, *, Omar Ahmed Mohamed Edbeib ${ }^{1}$, Aisha Douma ${ }^{2}$ and Ibrahim Imbayah Khalefah \\ Imbayah ${ }^{3}$ \\ ${ }^{1}$ Mechanical and Industrial Engineering Department, Bani Waleed University, Bani Waleed, Libya. \\ 2 Department of Computer Engineering, Atilim University, Ankara, Turkey. \\ ${ }^{3}$ Department of Electrical and Electronics, Higher Polytechnic Institute, ALShati, Libya.
}

Global Journal of Engineering and Technology Advances, 2021, 06(03), 081-087

Publication history: Received on 31 January 2021; revised on 02 March 2021; accepted on 05 March 2021

Article DOI: https://doi.org/10.30574/gjeta.2021.6.3.0040

\begin{abstract}
This study aims to highlight the electric vehicles revolution and its future in the Arab countries and the extent to which these countries are prepared for this modern industrial technology. This study divided into three main parts: The first part shows the historical introduction in electric vehicle manufacturing and how do electric vehicle works? While the second part presents the extent of the world's interest in electric vehicle technology, and the third part is devoted to evaluating the global electric vehicle sales and the future of electric vehicles in the Arab world, as recent few years have witnessed a remarkable official trend to introduce sustainable vehicles into the Arab world, along with a group of youth initiatives aimed at developing environmentally friendly green vehicles, which constitute an ambitious step to keep pace with the latest technologies and keep pace with global awareness of the need to address For global warming and environmental conservation.
\end{abstract}

Keywords: Electric Vehicle; Vehicle Manufacturing; Climate Change; Electric Motor.

\section{Introduction}

Since the emergence of the internal combustion engine at the end of the nineteenth century, specifically its installation and use in wheeled vehicles; motor vehicles have caused pollution because of their emissions into the environment. The degree of this pollution has increased over time as more and more vehicles appear on the roads over the years. It was only in the early 1950s when air pollution and vehicle first linked by a California researcher who determined that vehicle traffic was the cause of the hazy skies over Los Angeles. [1]

While the development of the internal combustion vehicle powered by gasoline or electric has been in full swing during the past century, the development of the electric vehicle has lagged behind. This changed the invention of the transistor during the forties of the twentieth century, when in 1947 one of the companies began producing the first electricpowered car, and by using the transistor it was able to produce a car called Henney Kilowatt.

The electric vehicle is a vehicle that works using electric energy, and there are many applications for its design, one of these applications is to replace the original engine of the vehicle and put an electric motor in its place. It is the easiest way to convert petroleum to electricity while preserving the other components of the vehicle. The engine is provided with the necessary energy through electric current from batteries. The electric vehicle differs from an electric vehicle

\footnotetext{
* Corresponding author: Abdussalam Ali Ahmed

Mechanical and Industrial Engineering Department, Bani Waleed University,Bani Waleed/Libya. 
in that it is a private vehicle for people, while an electric vehicle or vehicle is for industrial use or transporting people within the workplace and in public transport.

An electric vehicle uses an electric motor to drive the wheels. It derives some or all of its power from large, rechargeable batteries. The distance an electric vehicle can drive between recharges is known as its range [2].

There are three different categories of the electric vehicle include 1: Battery Electric Vehicles (BEVs), 2: Plug-in Hybrid Electric Vehicles (PHEVs), and 3: Hybrid Electric Vehicles (HEVs).

\subsection{Battery Electric Vehicles (BEVs)}

Battery Electric Vehicles, also called BEVs and more frequently called EVs, are fully electric vehicles with rechargeable batteries and no gasoline engine. All energy to run the vehicle comes from the battery pack that is recharged from the grid. BEVs are zero emissions vehicles, as they do not generate any harmful tailpipe emissions or air pollution hazards caused by traditional gasoline-powered vehicles, figure 1 shows the structure of the battery electric vehicle (BEV).

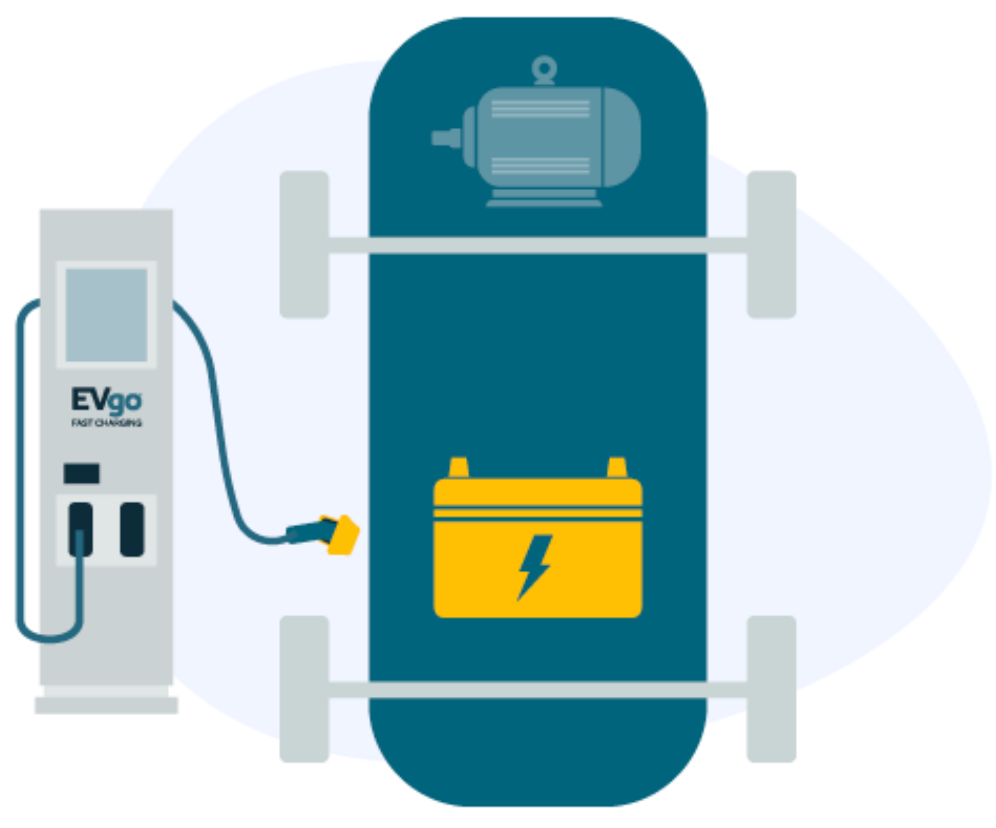

Figure 1 The battery electric vehicle structure.

\subsection{Plug-in Hybrid Electric Vehicles (PHEVs)}

Plug-in Hybrid Electric Vehicles, or PHEVs, have both an engine and electric motor to drive the car. Like regular hybrids, they can recharge their battery through regenerative braking. They differ from regular hybrids by having a much larger battery, and being able to plug into the grid to recharge. While regular hybrids can (at low speed) travel 1-2 kilometers before the gasoline engine turns on, PHEVs can go anywhere from 15-65 kilometers before their gas engines provide assistance. Once the all-electric range is depleted, PHEVs act as regular hybrids, and can travel several hundred miles on a tank of gasoline. 


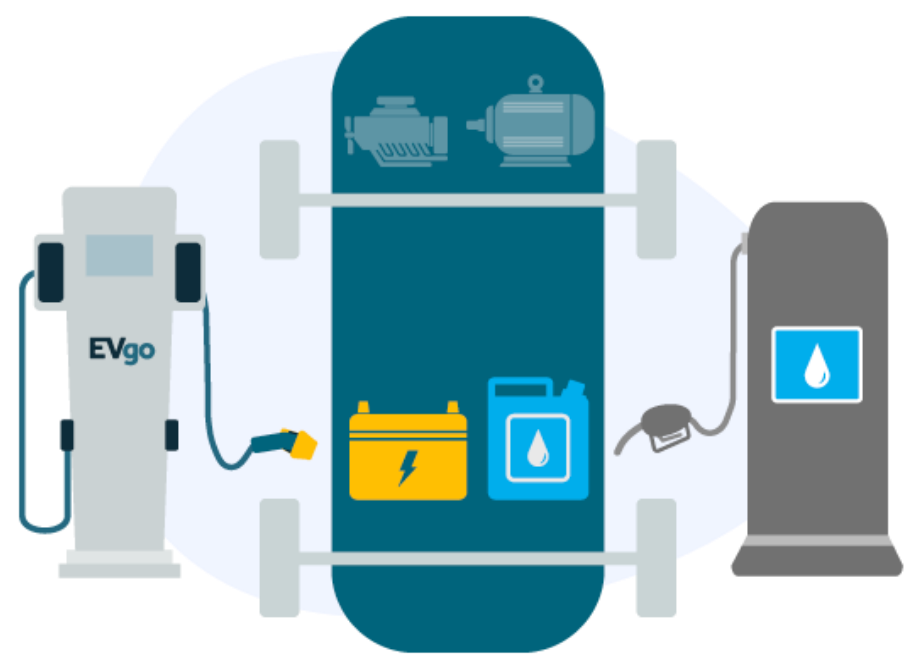

Figure 2 The plug-in hybrid electric vehicle structure.

\subsection{Hybrid Electric Vehicles (HEVs)}

Hybrid Electric Vehicles, or HEVs, have both a gas-powered engine and an electric motor to drive the car. All energy for the battery is gained through regenerative braking, which recoups otherwise lost energy in braking to assist the gasoline engine during acceleration. In a traditional internal combustion engine vehicle, this braking energy is normally lost as heat in the brake pads and rotors.

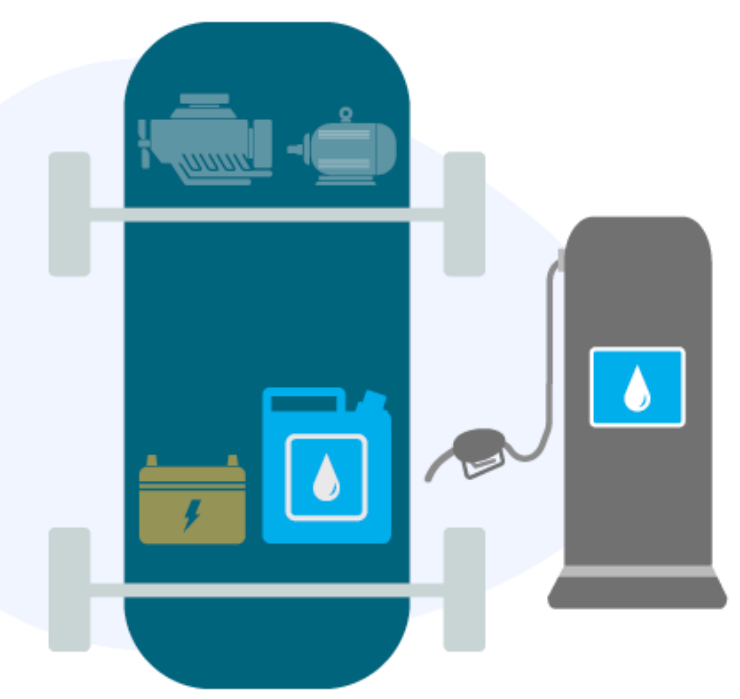

Figure 3 The hybrid electric vehicles structure.

\section{Why do we need Electric Vehicles?}

In addition to reducing emissions, electric vehicles provide many benefits to drivers and there are top five reasons to choose an electric vehicle.

- $\quad$ Electric vehicles save you money.

- Electric vehicles cut your emissions,

- Electric vehicles offer you a better driving experience.

- Electric vehicles cut your oil use.

- Electric vehicles are convenient. 


\section{The global electric vehicle sales}

Global sales of electric vehicles increased very quickly in 2020, rising by $43 \%$ to more than 3 million vehicles, despite the decline in overall sales of conventional cars by $20 \%$ during the COVID-19 pandemic according to the British newspaper "The Guardian".

Despite the difficult conditions and the negative impact of the COVID-19 pandemic on the vehicle industry but electric vehicle manufacturing made a huge leap in many countries in 2020.

According to estimates by the EV-Volumes Industry Tracker, electric vehicle sales accounted for $4.2 \%$ of global light vehicles last year up from $2.5 \%$ in 2019.

A year before the COVID-19 epidemic, only eight countries reported an increase in the share of electric vehicles to more than 5\%, while 13 countries were able to push electric vehicles to more than $10 \%$ of sales of new light vehicles in 2020 .

Norway retained the lead, with electric vehicles reached for $75 \%$ of vehicle sales in 2020 , while Iceland, Sweden and Finland also ranked the top five - a testament to the rapid adoption of electric vehicles in Nordic countries according to German data site Statista. It is "Al Arabiya.net".

China, which is the largest electric vehicle market in terms of sales, slipped out of the top ten with electric vehicles accounting for $6.2 \%$ of passenger car sales in the country. Meanwhile. The United States fell further, with a share of only $2.3 \%$.

Figure 4 illustrates the countries with the highest share of plug-in electric vehicles in new passenger car sales in 2020.

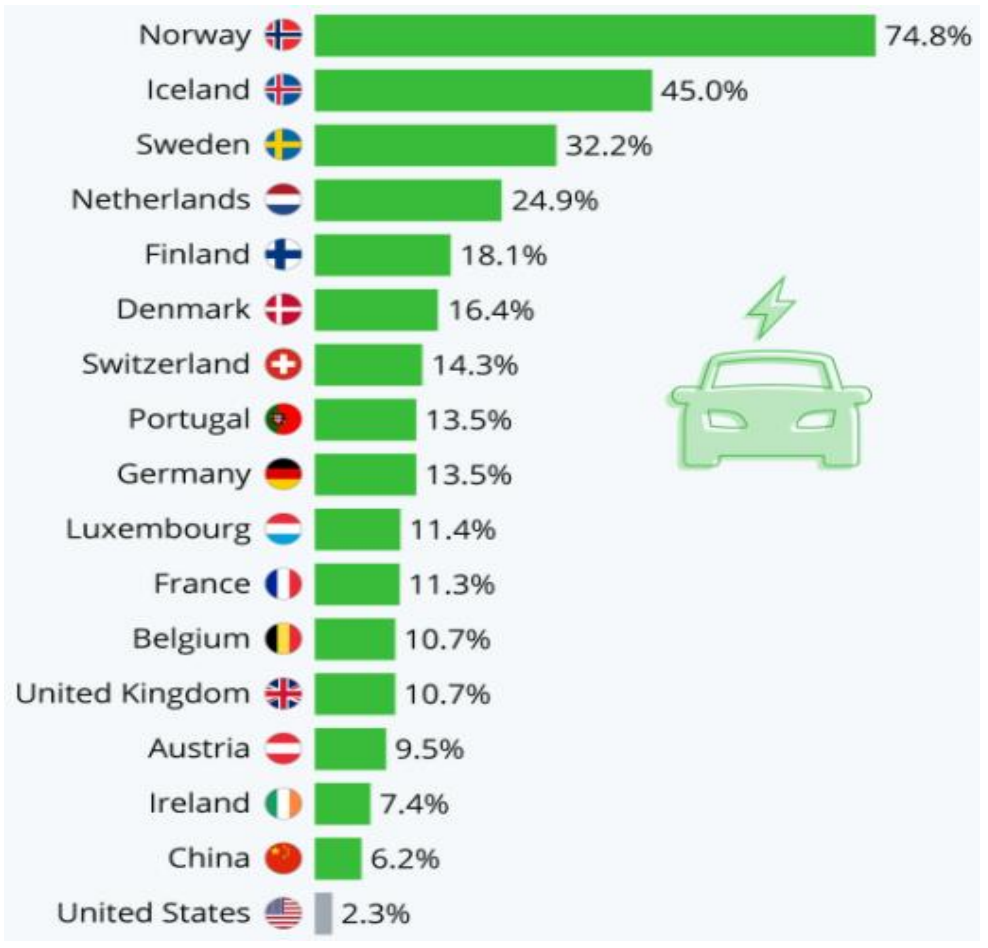

Figure 4 The electric vehicle sales in 2020.

To illustrate the increase in electric vehicle sales in the world, it can be seen through Figure 5 that shows monthly sales during the years 2018, 2019, and 2020. 


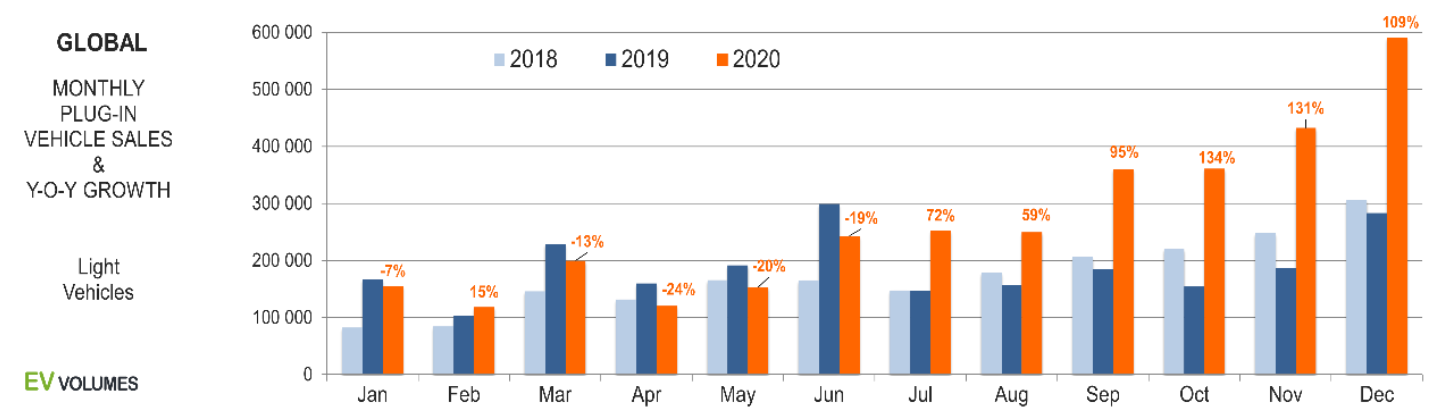

Figure 5 Global monthly plug-in vehicle sales in 2018,2019, and 2020.

It is obvious that in the previous figure that the electric vehicle industry is witnessing a great increase around the world, and this may constitute an economic problem for some oil and gas exporting countries. Figure 6 shows the electric vehicle share in the Sustainable Development Scenario, 2000-2030. [3]

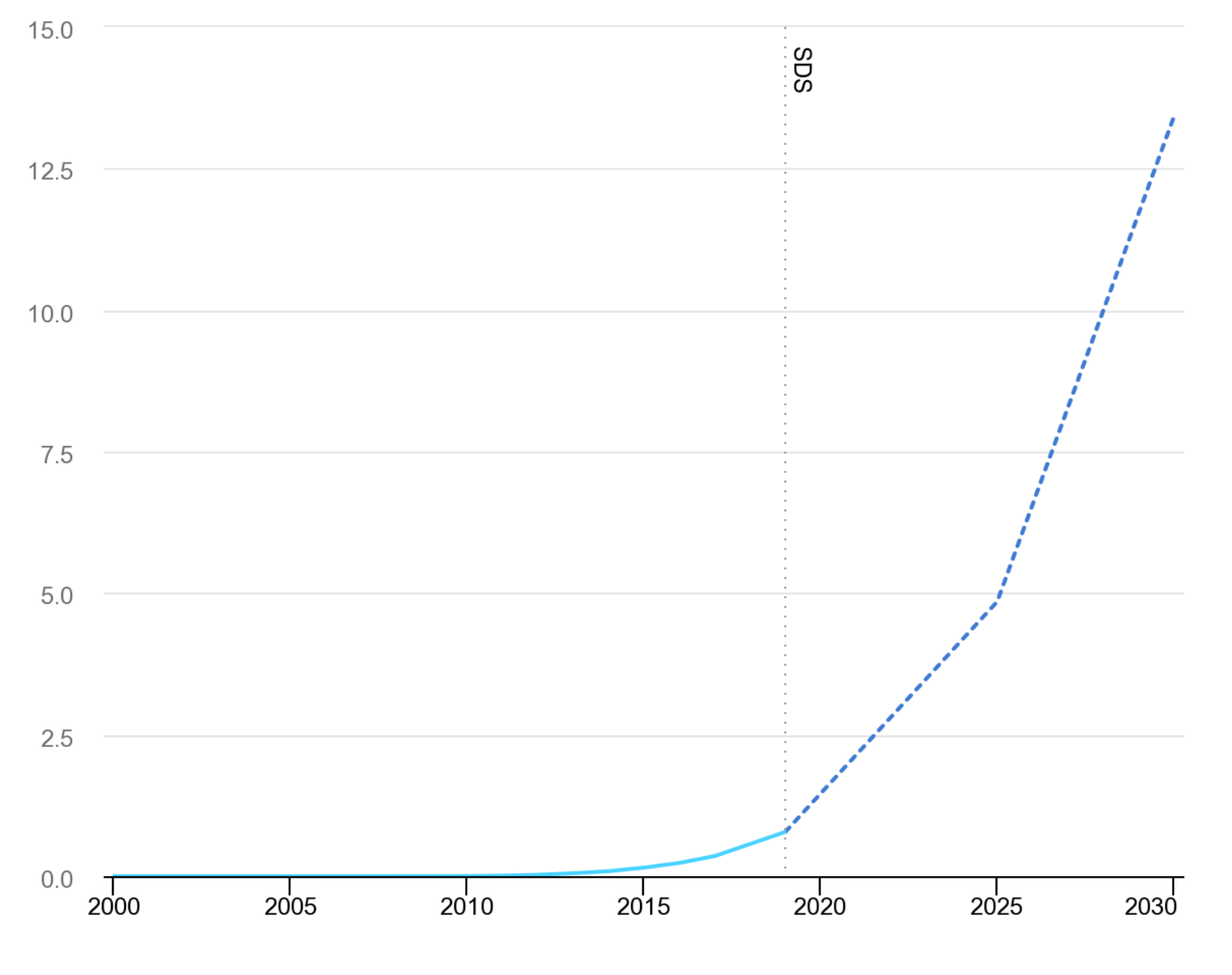

Figure 6 Electric vehicle share in the Sustainable Development Scenario, 2000-2030.

\section{Electric Vehicles in the Arab Countries}

In fact, most of the Arab countries did not have a noticeable interest in electric vehicles, especially the Arab countries located on the African continent. However, there are some Arab countries such as Jordan, the UAE, Saudi Arabia, Oman, Morocco, and Egypt that have witnessed in recent months a remarkable official trend to introduce electric vehicles into the Arab world, along with a group of Youth initiatives aimed at developing environmentally friendly green vehicles, which constitute ambitious steps to keep pace with the latest technologies and keep pace with global awareness of the need to address global warming and preserve the environment. 
The total purchases of electric vehicles in the Arab countries in 2018 amounted to approximately \$159.5 million, to account for a share of $2.6 \%$ of the total purchases of all countries in the world in the category of vehicles powered by a fully electric motor, which was estimated at \$ 10.6 billion, according to statistics issued by the Canadian website WTEx which is concerned with global market news and trends, and export opportunities by focusing on the largest and fastest exporting and importing countries. It is also concerned with publishing studies and reports about important export issues and monitoring and tracking global trade movement. The following figure shows the Arab countries' purchases of electric vehicles in million US dollars during 2018 and their share of the total world purchases.

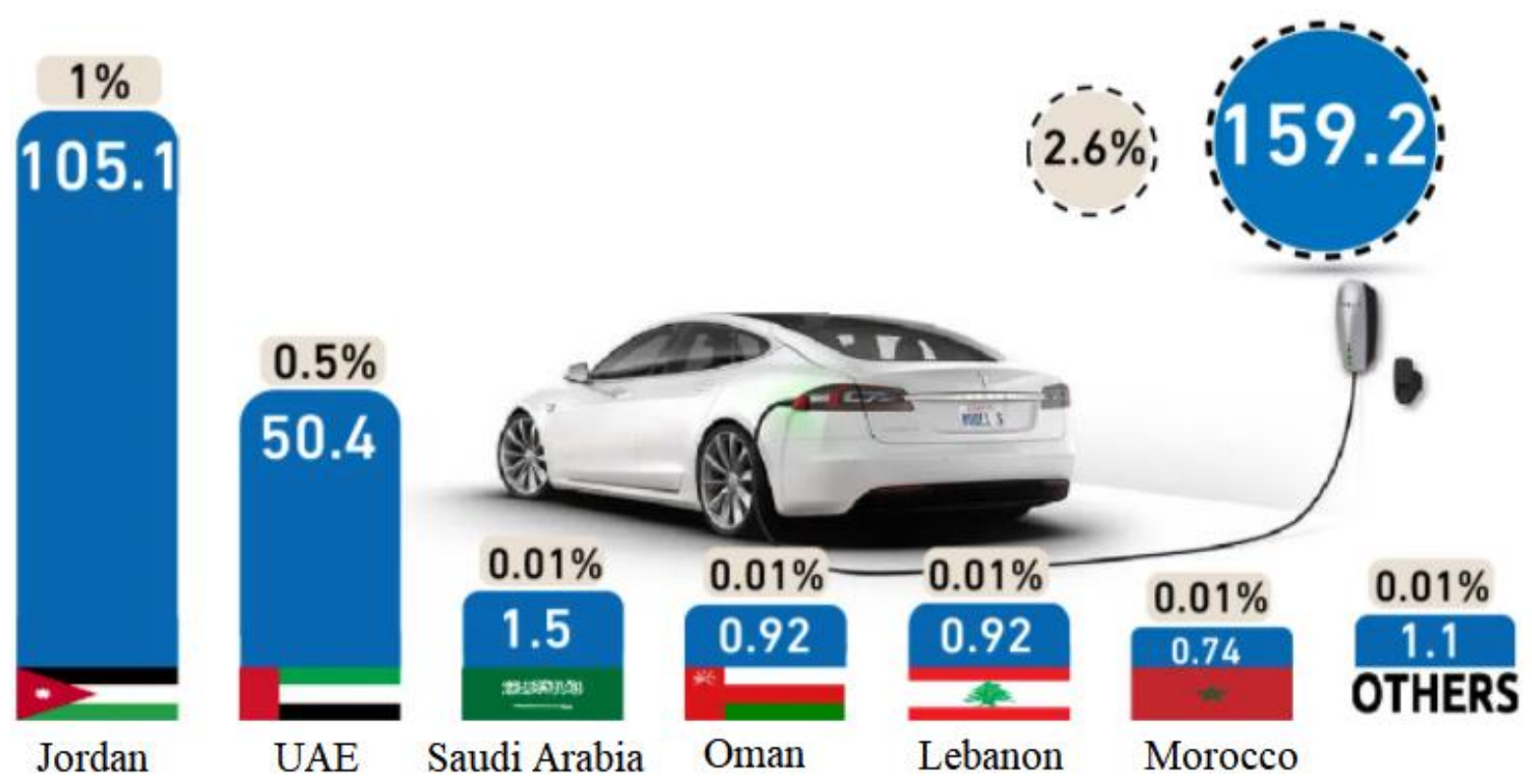

Figure 7 The Arab countries' purchases of electric vehicles in 2018.

\subsection{The necessity to regulate the electric vehicle sector in the Arab countries}

After several Arab countries implemented practical steps to introduce smart and sustainable vehicles to their streets, the need to regulate the sector, issue laws and legislations related to it, and prepare the infrastructure for it, and from here stems the importance of conducting experiments and operating those subject vehicles to the control of specialists and government agencies.

\subsection{Infrastructure creation}

Arab countries have taken practical steps to prepare the infrastructure to receive electric cars, while other countries have set ambitious plans for the same goal. In this context, Saudi Arabia's efforts to increase reliance on electric cars and to boost their demand locally, as the global Schneider Electric Company expected, in 2019, that The Kingdom will open five fast-charging stations for electric cars in the near future, and attributed that to receiving requests to implement electric charging stations for cars in the last quarter of 2018 for commercial and residential projects.

\subsection{Challenges of using electric vehicles in the Arab countries}

Challenge 1: There are not yet appropriate models that can appeal to some Arab mass-market.

Challenge 2: People do not want to change the way they drive.

Challenge 3: EV charging tariffs need to reflect the system cost.

Challenge 4: Private sector participation in charging ownership and operation is limited. 


\section{Conclusion}

This paper showed some important concepts related to electric vehicles in terms of the historical view, how they work, as well as the types of electric vehicles. The paper also showed the rapid increase in demand for electric vehicles and the rate of countries' sales of them in the world. The critical part of this work was to use electric vehicles in Arab countries and how there are some countries that witnessed a remarkable increase in the use of electric vehicles such as Jordan, Oman, the United Arab Emirates, Egypt, Lebanon and Morocco. There are other Arab countries that have not worked to introduce electric vehicle technology till this time such as Libya, Tunisia, Mauritania, Sudan and other Arab countries but we expect that all of these countries will import electric vehicles in the near future due to their importance in minimizing air pollution and the lack of frequent need for maintenance.

\section{Compliance with ethical standards}

\section{Disclosure of conflict of interest}

The authors declare no conflict of interest.

\section{References}

[1] U.S. Environmental Protection Agency, Office of Mobile Sources, Milestones in Auto Emissions Control, 1994.

[2] David Hirst, Electric vehicles and infrastructure, House of Commons Library, Number CBP07480, 4 December 2020.

[3] IEA 2020, Electric Vehicles, IEA, Paris https://www.iea.org/reports/electric-vehicles.

[4] Z S Gelmanova, G G Zhabalova, G A Sivyakova, O N Lelikova, O N Onishchenko, A A Smailova, S N Kamarova, Electric cars. Advantages and disadvantages, IOP Conf. Series: Journal of Physics: Conf. Series 10152018052029 doi :10.1088/1742-6596/1015/5/052029.

[5] Sharon L. Poczter and Luka M. Jankovic, General Motors: The Electric Revolution, Journal of Business Case Studies, 2014; Vol. 10:No. 2.

[6] M. Guarnieri, "Looking back to electric cars," 2012 Third IEEE HISTory of ELectro-technology CONference (HISTELCON), Pavia, Italy, 2012; pp. 1-6, doi: 10.1109/HISTELCON.2012.6487583. 